\title{
JAMES HARRINGTON E A RELAÇÃO ENTRE VIRTUDE E RIQUEZA
}

\section{ALBERTO RIBEIRO GONÇALVES DE BARROS ${ }^{1}$}

RESUMO: A intenção é discutir a interpretação de John Pocock de que o republicanismo de James Harrington condenaria a riqueza proveniente da atividade mercantil, na medida em que ela comprometeria o exercício da virtude cívica dos cidadãos. A primeira parte do artigo pretende esclarecer que a sua teoria sobre o fundamento econômico do poder político também se aplica às nações mercantis, ao destacar passagens da obra de Harrington em que a base material do governo não é apenas a propriedade da terra, mas também a propriedade de mercadorias e bens monetários. A segunda parte espera demonstrar que a sua concepção de virtude está principalmente vinculada às instituições e aos dispositivos constitucionais que asseguram a autoridade ao governo. Enfim, o objetivo é mostrar que a relação entre virtude e riqueza é de complementaridade, independentemente do tipo de republica, agrária ou comercial, na medida em que elas são os dois fundamentos do governo.

PALAVRAS-CHAVE: Harrington, virtude, riqueza, governo, republicanismo.

ABSTRACT: The intention is to debate John Pocock's interpretation that James Harrington's republicanism would disapprove the wealth derived from commercial activities, because it would compromise the exercise of citizens' civic virtue. The first part of the article aims to clarify that his theory on the economic foundation of political power also applies to mercantile nations, by highlighting passages in Harrington's work in which the government's material basis is not only lands, but also merchandises and trade. The second part hopes to demonstrate that his conception of virtue is mainly related to the constitutional institutions and devices that grant authority to the government. Then, the purpose is to show that the relationship between virtue and wealth is complementary, regardless of the type of republic, agrarian or commercial, inasmuch as they are the two foundations of the government.

KEYWORDS: Harrington, virtue, wealth, government, republicanism.

Em The Machiavellian Moment: Florentine Political Thought and the Atlantic Republican Tradition (1975), John Pocock atribuiu um lugar central a James Harrington na transposição de uma linguagem empregada pelos humanistas cívicos da Renascença italiana, em particular por Maquiavel, que valorizava a virtude e a participação política dos cidadãos,

\footnotetext{
${ }^{1}$ Professor do Departamento de Filosofia da USP. Mestre, Doutor e Livre-Docente pela mesma instituição. Desenvolveu pesquisa de pós-doutorado no Royal Holloway College - University of London (2009), no Institute of Historical Research - University of London (2013) e na Université Paris 1 Panthéon-Sorbonne (2019). Pesquisador do CNPq, com bolsa produtividade. O artigo é produto desta pesquisa. E-mail: abarros@usp.br.
} 
para o debate político inglês. Pocock (1975, p. 383-400) considera o republicanismo de Harrington uma clara manifestação da linguagem da virtude, que teria sido transmitida da Florença renascentista para a Inglaterra seiscentista, de onde teria migrado para as colônias americanas, vindo a influenciar de maneira decisiva a luta pela independência e a formação da República norte-americana. Sustentada em categorias aristotélicas, principalmente na concepção de que o ser humano é um animal político, que só desenvolve sua natureza moral e política quando participa da ação coletiva na construção de sua comunidade política, ela enfatizava a necessidade da virtude cívica, do engajamento na vida pública e da devoção ao bem comum.

Em um artigo posterior, "The Machiavellian Moment Revisited” (1981), Pocock reiterou que essa linguagem política foi adotada por Harrington em sua proposta constitucional para Oceana, espelho ficcional no qual é projetada a Inglaterra de seu tempo. Ao recorrer ao ideário republicano, em particular à importância da virtude cívica dos cidadãos, ele teria optado por um modelo de república agrária de pequenos proprietários de terras, autossuficientes, armados e prontos para lutar pela sua liberdade, em detrimento das modernas nações mercantis cuja multiplicação da riqueza por meio do comércio representaria um fator de corrupção que ameaçaria a estabilidade e a longevidade da república. Nesse sentido, o seu republicanismo seria hostil à riqueza, em particular àquela proveniente da atividade comercial, na medida em que ela comprometeria o exercício da virtude cívica.

No entanto, a interpretação de que virtude e riqueza são antagônicas no pensamento político de Harrington parece ser, no mínimo, problemática. No início da "Primeira Parte das Preliminares" de The Commonwealth of Oceana (1656), discurso que antecede a constituição proposta para Oceana e no qual se encontra os princípios de sua teoria política, Harrington (1997, p. 10) classifica os fundamentos do governo em dois tipos: os bens da mente, ou seja, as virtudes naturais e adquiridas que conferem autoridade; e os bens da fortuna, isto é, as riquezas em geral que asseguram poder ou império ${ }^{2}$. Assim, riqueza e virtude não aparecem em oposição, mas numa relação de complementaridade, tendo em vista que são os dois fundamentos - material e moral - do governo. Trata-se então de compreender como a virtude suscita autoridade e como a riqueza gera império, sem que a riqueza comprometa a virtude.

\footnotetext{
${ }^{2}$ Harrington reconhece que existem outros bens, como os bens do corpo - beleza, saúde, etc. - mas eles não são decisivos para a aquisição de autoridade ou império (HARRINGTON, 1977, p. 10-11). A mesma divisão de bens pode ser encontrada em Platão (2002, 697 a-d) e em Aristóteles (1989, 1323 a 25-1323 b 15).
} 
I.

De acordo com Harrington (1997, p. 10), o império no interior de uma nação é baseado no domínio, definido como a propriedade real ou pessoal, isto é, a propriedade agrária ou monetária. Embora o domínio possa ser expresso de diversas maneiras - terras, mercadorias ou dinheiro - a propriedade da terra é tomada como o principal fundamento do império, talvez porque seja um bem mais sólido e concreto do que outros bens da fortuna.

Apesar da importância da propriedade da terra na argumentação de Harrington, não há qualquer comentário a respeito de sua origem. Só no início de The Art of Lawgiving (1659), Harrington faz algumas observações de forma muito concisa sobre como a propriedade se origina. Referindo-se ao texto bíblico segundo o qual a terra foi dada aos homens, para que pudessem viver do suor de seu rosto (Salmos 115, 16), ele argumenta que o dom divino veio com a condição da incorporação do trabalho (HARRINGTON, 1771, p.442). Desse modo, muito antes da teoria de Locke (2000, cap.5) sobre a origem da propriedade, o trabalho é considerado a única forma lícita de apropriação da terra. Somente com a atividade laboriosa dos homens, que se manifesta nas ações do corpo e da mente, o direito sobre a terra se justifica.

A relação entre a propriedade da terra e o império é demonstrada pela dependência estabelecida entre o proprietário e aqueles que dependem dele. O exemplo dado é esclarecedor: se alguém é capaz de prover alimentos para outras pessoas, elas dependem dele para sobreviver e estão assim sob o seu domínio; do mesmo modo, quem detém a propriedade da terra e, consequentemente, a produção de alimentos, detém o domínio sobre aqueles que dependem dele para sobreviver. Por isso, a propriedade da terra assegura o império (HARRINGTON, 1771, p. 499).

Na avaliação de Harrington (1997, p.11-12), quando o império se baseia na propriedade da terra, o regime político é determinado pela proporção na posse das terras entre os membros do corpo político, o que ele denomina de balanço do domínio. Seguindo a tipologia clássica, três possibilidades são apresentadas: se um único homem possui a maior parte das terras de uma nação, como na Turquia, o balanço é monárquico e o império é uma monarquia absoluta; se um pequeno número de homens a possui, dividindo as terras entre si, como na Espanha ou na Polônia, o balanço é gótico e o império é uma monarquia temperada ou uma aristocracia; e se o povo a possui, dividindo as terras de maneira igualitária, como em Oceana, o balanço é popular e o império é uma república. Assim, o balanço do domínio determina o regime político, de tal forma que uma variação na proporção provoca uma mudança inevitável de império. 
De acordo com Harrington (1997, p. 12), no caso do uso da violência, o império deixa de ser natural e torna-se fruto da posse das armas. O resultado é então a tirania, a oligarquia ou a anarquia, dependendo do número de pessoas que controlam as armas: uma, algumas ou muitas. Como nesses casos o poder político é mantido apenas pela força das armas, todas as formas de governo são consideradas instáveis, uma vez que o império não está fixado pelo balanço do domínio.

Assim, a corrupção do regime político não é avaliada segundo as razões tradicionalmente evocadas - degradação moral, distância temporal do momento da fundação do corpo político, manifestação de elementos corruptíveis da forma de governo, entre outros mas em função da interferência da força, que se opõe ao balanço do domínio. Em outros termos, a corrupção não provém de uma deterioração moral ou de uma falha intrínseca do regime político, mas do exercício do poder pela força das armas em oposição ao balanço do domínio.

Hobbes é novamente criticado por ter considerado a força o único fundamento do governo e sustentado que nenhum governo pode prescindir da espada, visto que as leis civis, sem a ameaça de coerção, não passam de palavras ao vento (Cf. HOBBES, 1985, p. 231). Mas, se é verdade que todo governo se fundamenta apenas na espada, Harrington questiona o sentido do pacto entre os indivíduos na origem do corpo político, tal como descrito pelo autor do Leviathan (1651). Hobbes é ainda censurado por ter vinculado o poder político ao comando da espada, sem ter dito nada sobre quem a controla (Cf. HOBBES, 1985, p.669). O argumento de Harrington é que deve haver uma mão para empunhar a espada, caso contrário ela é apenas um ferro frio; e a mão que a empunha, impondo a obediência pelo medo, é o exército. Como o exército é um animal faminto com grande estômago, que deve ser constantemente mantido, quem o alimenta tem o seu comando e, portanto, o meio coercitivo necessário para assegurar a obediência política (HARRINGTON, 1997, p. 13).

O princípio de que o império se baseia no balanço do domínio é então reforçado com a necessidade do controle das armas, pois quem detém a propriedade das terras pode manter um exército e, desse modo, ter seu comando e exercer com mais segurança o poder político. No caso de um desequilíbrio entre o controle das armas e a propriedade das terras, o resultado é a instabilidade, como ocorreu em Roma, onde o povo detinha as armas e os nobres possuíam a maior parte das terras. Esta assimetria predispôs ao conflito, gerando dissensões contínuas entre o povo e a nobreza, o que causou a ruína da República romana.

De acordo com Harrington, a fim de conservar o balanço popular, fundamental para assegurar a manutenção de uma república, é fundamental estabelecer uma lei agrária. Esta lei 
teria sido introduzida por Deus, quando dividiu as terras de Canaã ao seu povo, e depois foi instituída por Licurgo, a fim de preservar a distribuição de terras entre os cidadãos de Esparta. A estabilidade daquela cidade foi mantida, enquanto foi preservada a proporção ordenada por Licurgo, sendo depois perdida com a posterior alteração na distribuição das terras. Isso provaria a importância da lei agrária, que é considerada por Harrington a primeira lei fundamental de uma república. (HARRINGTON, 1992, p.10-2).

Em The Prerrogative of Popular Government (1658), Harrington argumenta que a lei agrária pode fixar o balanço do domínio de diversas formas, por exemplo, concedendo as terras a certas famílias, sem autorizar a sua alienação, como em Esparta, ou limitando a propriedade de terras, de tal modo que ninguém possa exceder a proporção estabelecida, como na constituição proposta para Oceana. Ela não visa um nivelamento absoluto, que imponha uma igualdade irrestrita na propriedade das terras, mas uma limitação da desigualdade, por meio de uma distribuição equitativa, de tal modo que um homem, ou um pequeno número de homens, não possa ter mais terras do que o povo. Sem a sua instituição, qualquer que seja o regime político, não haverá estabilidade e nem longevidade para o corpo político (HARRINGTON, 1771, p. 338).

A relação entre a propriedade das terras e o império é ilustrada na "Segunda Parte das Preliminares", por meio de uma narrativa da história da Inglaterra, desde a origem do balanço gótico até a sua substituição pelo balanço popular. O ponto mais importante dessa narrativa é o momento em que a monarquia inglesa entrou em colapso como resultado de uma política real de enfraquecimento da nobreza, com a alienação de suas terras e de seus ofícios. Ao ambicionar uma monarquia absoluta, os reis ingleses arruinaram a fundação de seu próprio poder, que estava na força militar da nobreza. Eles também possibilitaram a ascensão militar e política da Câmara dos Comuns, por meio de uma redistribuição mais igualitária das terras entre o povo. Os monarcas ingleses foram assim os principais responsáveis pela substituição do balanço gótico pelo popular e, consequentemente, pelo estabelecimento da república. Desse modo, as guerras civis não provocaram o fim da monarquia, mas foram simplesmente a consequência da alteração no balanço do domínio; e a república já estava em germe com a consolidação do balanço popular (HARRINGTON, 1992, p.53-6).

Pocock (1975, p. 384-6) vê a narrativa histórica da "Segunda Parte das Preliminares" como crucial para a compreensão do pensamento político de Harrington. Ele enfatiza o seu caráter inovador, na medida em que ela explica o declínio da nobreza e a ascensão militar e política do povo não apenas pela alteração do balanço do domínio, mas também pela ideia de 
que a posse das armas está baseada na propriedade das terras. Desse modo, na interpretação de Pocock, a noção maquiaveliana de que a cidadania se manifesta principalmente na virtude militar - em Roma, a virtù militar possibilitou aos plebeus o exercício da virtù cívica, universalizando a ação política e, consequentemente, a experiência da liberdade como participação na vida pública - se alia a uma nova ideia: a propriedade das terras permite o controle das armas, o que garante o poder político decorrente do balanço do domínio. Pocock admite que Harrington estava ciente do desenvolvimento comercial da Inglaterra e da importância do mercado tanto para os produtos provenientes do cultivo das terras quanto para a compra e vendas das próprias terras, mas esses fenômenos econômicos não tinham um papel decisivo em sua explicação para o processo de substituição do balanço gótico pelo popular.

No entanto, apesar da predominância da propriedade das terras, não se pode esquecer que são mencionados outros fundamentos do império. Harrington (1992, p. 12-3) comenta, por exemplo, os casos de nações em que o território é muito pequeno ou as terras não são um fator econômico relevante, ou ainda em que a riqueza está mais concentrada em mercadorias e bens monetários do que em terras. Nessas nações, o império está fundado na propriedade das mercadorias e dos bens monetários, que são também uma forma de expressão da riqueza. Ele ainda se refere explicitamente à Holanda e Gênova, onde o montante das transações comerciais e dos bens monetários era mais relevante do que a propriedade das terras. A diferença ressaltada é que a mobilidade e a volatilidade dessa forma de riqueza tornavam o império mais instável, já que ele se encontrava fixado, nas palavras de Harrington, nas asas do vento.

Em A System of Politics (1661), Harrington (1992, p. 270) alega que, se a riqueza de um homem pode estar mais concentrada em mercadorias e bens monetários do que na propriedade de terras, o mesmo não ocorre geralmente com as nações, com exceção daquelas que têm sua riqueza determinada mais pelo comércio do que pelo seu território. Em The Prerrogatives of Popular Government, ele cita três casos em que isso acontece: onde não há propriedade da terra, como na Grécia arcaica; onde a terra está tão dividida, como entre os israelitas nos tempos bíblicos, que a sua propriedade é irrelevante; e onde o território é muito pequeno e insuficiente para alimentar a população, como em Gênova e na Holanda. Em seguida, Harrington (1771, p. 288-289) ilustra a relação de dependência que se estabelece com base na propriedade dos bens monetários: por exemplo, se 1000 libras por ano são suficientes para um homem ter um servo, aquele que tiver 100 vezes esse valor poderá ter 100 servos; e se esse valor for multiplicado por mil, poderá ter 100.000 servos. Desse modo, como na propriedade das terras, a propriedade dos bens monetários permite as condições materiais para o exercício do poder. No caso das nações, 
quanto mais concentrada a propriedade dos bens monetários, mais o balanço é monárquico e o império se aproxima de uma monarquia absoluta; e, pelo contrário, quanto mais disperso, mais próximo estará de um balanço popular e, consequentemente, de uma república.

A ideia central nessas considerações é de que o poder político, assim como o domínio pessoal, tem sua origem na relação de dependência: quem não possui propriedade - terras ou mercadorias e bens monetários - depende de quem a possui para sobreviver e, portanto, está sujeito à vontade de seu proprietário. Numa monarquia absoluta, na qual o monarca é proprietário da maior parte das terras do reino, os seus súditos dependem dele para sobreviver e, desse modo, estão submetidos à sua vontade. No caso de uma república, cuja principal marca é a liberdade, que se caracteriza pela ausência de submissão, os cidadãos não devem estar submetidos à vontade arbitrária de ninguém. Dessa forma, a existência e a manutenção de uma república exige a distribuição a mais igualitária possível da riqueza entre os seus cidadãos, de modo a garantir a independência dos cidadãos, que assegura, por sua vez, a liberdade.

$\mathrm{Na}$ "Primeira Parte das Preliminares" de The Commonwealth of Oceana, Harrington (1992, p.14) menciona Aristóteles como aquele que alertou para as consequências da riqueza imoderada em uma república, cuja estrutura igualitária não permite qualquer preeminência entre os cidadãos. No entanto, a citação parafraseada não é totalmente fiel ao texto da Política. $\mathrm{Na}$ verdade, Aristóteles $(1989,1302$ b 15-20) alerta para o risco de uma mudança de regime numa cidade democrática, quando alguns cidadãos passam a ter uma preeminência exagerada em relação aos outros, mas sem especificar que ela é econômica. A sua preocupação parece ser mais a injustiça na distribuição de funções, honras ou benefícios do que a distribuição de riqueza entre os cidadãos.

Em The Prerrogatives of Popular Government, a mesma passagem é citada, com a mesma interpretação, a fim de atribuir ao filósofo grego a origem da ideia de que a estabilidade de um regime político depende do equilíbrio entre o balanço do domínio e o império. Para reforçar seu argumento, Harrington (1771, p. 342) refere-se à passagem em que Aristóteles $(1989,1303$ a) trata dos riscos do crescimento desproporcional de uma das partes da cidade, em particular o aumento excessivo do número de pobres ou de ricos. Ele refere-se também à passagem na qual é examinado o problema da injustiça com aqueles cidadãos que se destacam pelo mérito e pela virtude nas cidades cujas leis tratam a todos de maneira igualitária; e a solução do ostracismo para lidar com a eminência desses cidadãos (Cf. ARISTÓTELES, 1989, 1284 a). Novamente a situação de preeminência é interpretada por Harrington (1771, p. 338) 
no aspecto econômico; e o ostracismo é comparado com a intervenção da lei agrária, no sentido de um procedimento legal capaz de manter a estabilidade de um governo popular.

Harrington $(1771$, p. 339) cita ainda outras passagens da Política, com o intuito de mostrar que Aristóteles já havia alertado para o problema do excesso de riqueza em uma república. A passagem mais comentada é a avaliação da constituição proposta por Falêas, que preceitua a igualdade de propriedade entre os cidadãos a fim de evitar a discórdia civil. Mas Harrington ignora a crítica aristotélica aos que acreditavam que equalizar ou limitar a propriedade da terra resolveria o problema das dissensões civis. Por exemplo, em seu comentário à constituição proposta por Falêas, Aristóteles (1989, 1266 a - 1267 b) argumenta que é necessário igualar os desejos e não a propriedade, visto que a discórdia civil é causada não tanto pela distribuição desigual da riqueza quanto pela atribuição injusta de honras e benefícios.

Harrington (1992, p. 15) alega que Maquiavel também reconheceu o problema da riqueza excessiva em uma república. De fato, Maquiavel (2007, p. 162-3) afirma que deve ser instituída uma república numa cidade onde haja igualdade entre os cidadãos, pois é necessário criar corpos políticos com alguma proporção para que possam ter longevidade. Mas a igualdade a que ele se refere não parece ser econômica. Ao enfatizar que a diferença social em Veneza jamais estabeleceu um direito a privilégios, Maquiavel parece indicar que essa igualdade é fundamentalmente política: todos os cidadãos venezianos podiam igualmente ocupar magistraturas e exercer funções públicas independentemente de sua condição social e econômica.

Apesar da interpretação problemática do pensamento político de Aristóteles e de Maquiavel, o aspecto a ser ressaltado é o princípio de que a liberdade, que caracteriza o regime republicano, se define pela ausência de submissão ou sujeição, garantida pela propriedade de terras ou de mercadorias e bens monetários: é necessário ter recursos materiais para ser independente e, assim, desfrutar da liberdade. Em uma república, seja ela agrária, seja ela mercantil, a distribuição igualitária da riqueza é essencial como condição da liberdade: "igualdade de bens causa igualdade de poder, e igualdade de poder é liberdade, não só da república, mas de cada um de seus membros "(HARRINGTON, 1992, p. 17). 
II.

Se a reflexão sobre o império se concentra nas bases materiais do governo, ou seja, no balanço do domínio da propriedade de terras ou de mercadorias e bens monetários, a autoridade é tratada a partir da perspectiva moral por meio da imagem da alma humana. Numa linguagem comum à sua época, Harrington (1992, p. 18) afirma que a alma humana é um campo de disputa entre razão e paixão. Quando a paixão se sobrepõe, o resultado é o vício e a escravidão, o que gera vergonha para si e desprezo dos outros. Ao contrário, com o triunfo da razão, o resultado é a virtude e a liberdade, o que resulta em honra para si e autoridade sobre os demais. Com base na tradicional metáfora do corpo político, o governo é então comparado à alma de uma nação, disputada pelas duas potências rivais: razão e paixão. Quando o governo é dirigido pela paixão, o vício se instala e o resultado é a tirania. Ao contrário, quando é guiado pela razão, tem-se a virtude e a liberdade:

Se a liberdade de um homem consiste no comando da razão, a sua ausência o precipitará na escravidão de suas paixões: portanto, a liberdade de uma república consiste no governo de leis, e a ausência das leis a entregará à ambição dos tiranos. Estes são os princípios nos quais entendo que Aristóteles e Tito Lívio [...] basearam a afirmação de que uma república é o governo de leis e não de homens (HARRINGTON, 1992, p.19)

Assim, a virtude e a liberdade dependem do governo de leis e a autoridade é adquirida quando as leis expressavam a razão. O problema reconhecido por Harrington é como as leis podem expressar a razão e visar o interesse público, se aqueles que as decretam são pessoas movidas pelas suas paixões e guiadas pelos seus interesses particulares. Inicialmente, ele refuta a concepção hobbesiana de que os seres humanos optam por seus interesses quando há uma oposição entre razão e interesse ${ }^{3}$, com o argumento de que a razão nada mais é do que o interesse, visto que ela conduz as pessoas à realização de seus interesses. Em seguida, ele postula que existem diferentes razões e, consequentemente, interesses diferentes:

Primeiro, há a razão privada, que é o interesse de um homem privado; depois, há a razão de estado, que é o interesse (ou erro, como era dito por Salomão) do governante ou dos governantes, isto é, do príncipe, da nobreza ou do povo; finalmente, há aquela razão que é o interesse do gênero humano ou do todo (HARRINGTON, 1992, p.21).

Se há diferentes interesses, é preciso estabelecer uma hierarquia entre eles, ou seja, uma escala entre as diferentes razões, já que elas não se encontram no mesmo nível de relevância.

\footnotetext{
${ }^{3}$ Harrington deve estar se referindo a afirmação feitas no início da Epístola Dedicatória de The Elements of Law Natural and Politic: "tão frequente como a razão está contra um homem, assim estará um homem contra a razão" (HOBBES, 1994, p.20). O sentido da afirmação, em seu contexto, é que todas as vezes que a razão se opõe aos interesses de um homem, o que acontece com frequência no debate público, é inevitável que o homem enfrente a razão por causa de seus interesses
} 
Com o intuito de provar que quanto mais amplo for o interesse, mais ele se aproxima da razão, Harrington cita uma longa passagem do jurista Richard Hooker, na qual se encontra a ideia de que, mesmo entre os agentes naturais desprovidos de razão, existe uma lei que os dirige para o bem do todo (Cf. HOOKER, 2013, I, III, 5). Desse modo, é preciso reconhecer tanto a superioridade do interesse do todo sobre o interesse das partes quanto a existência de uma lei natural que conduz todos os seres a buscar o bem do todo do qual fazem parte. Harrington argumenta então que, se o interesse da humanidade é superior ao interesse de qualquer ser humano em particular, a razão do gênero humano só pode ser superior à razão dos particulares e, por isso, deve ser considerada a reta razão.

A aplicação deste princípio na vida política é que quanto mais próximo o interesse de um governo estiver do interesse do todo, mais próximo ele estará da reta razão. Em A System of Politics, Harrington (1992, p. 217-218) reafirma que todo governo efetiva o seu interesse: numa monarquia absoluta, o interesse do rei é manter seu poder; numa monarquia regulada ou aristocracia, o interesse da nobreza é assegurar seus privilégios; e num governo popular, o interesse do povo é efetivar o seu bem-estar. Em sua avaliação, o governo cujo interesse está mais próximo da reta razão, por visar o interesse do todo, é o governo popular, já que o rei e a nobreza visam apenas os seus interesses particulares.

Harrington reconhece que ainda é necessário demonstrar que as leis estabelecidas em um governo popular podem exprimir a razão, assegurando a virtude e, consequentemente, gerando a autoridade. Nesse ponto, ele passa a se concentrar nos arranjos institucionais capazes de direcionar criaturas auto interessadas para a realização do interesse comum, indicando que a virtude almejada não é tanto a virtude daqueles que exercem o poder político, no sentido do bom governante, nem a virtude dos cidadãos, no sentido da participação na vida política, mas a virtude das instituições.

O problema admitido por Harrington (1992, p.22) é o de que como alcançar o interesse comum a partir de interesses particulares. A solução é ilustrada pelo dilema de duas meninas que se encontram diante de um bolo, desejado por ambas, e uma delas propõe para a outra: "divida e eu escolherei ou deixe-me dividir e você escolherá". Se a proposta for aceita por ambas, o interesse de cada uma será realizado, pois cada uma terá uma parte do bolo, e o interesse comum também será alcançado, já que ambas desfrutarão do bolo na mesma proporção. Isto porque a garota que vai dividir sabe que a outra vai escolher primeiro e ela vai procurar dividir da maneira mais proporcional possível, para ficar com um pedaço igual ao da 
garota que vai escolher primeiro. Conscientes de seu interesse particular, as duas garotas impõem a si mesmas uma regra para alcançar o interesse comum.

A sabedoria das duas meninas revela, segundo Harrington, todo mistério da vida política, que consiste na separação das funções de discussão e de deliberação no processo de elaboração das leis civis. Em linguagem política, dividir equivale a distinguir e avaliar as diferentes razões por meio do debate; e escolher equivale a decidir depois do exame do que foi apresentado. Em uma monarquia ou aristocracia, o rei ou a nobreza dividem e escolhem, ou seja, debatem e decidem. Desse modo, o interesse comum será avaliado e determinado pelo interesse particular do rei ou da nobreza; e as leis expressarão o interesse de uma parte do corpo político. Já em um governo popular, é possível separar o debate da decisão, de modo que o interesse comum pode ser definido e alcançado pela participação de todas as partes do corpo político na elaboração das leis.

Harrington (1992, p.22-3) admite que, se a separação de funções era indiferente entre as duas garotas, uma vez que cada uma podia dividir ou escolher, em um governo popular a discussão e a deliberação devem ser atribuídas aos mais competente para cada uma das tarefas. Em sua avaliação, Deus não deixou dúvidas sobre esta atribuição, separando a humanidade em duas ordens: um pequeno grupo de pessoas com a faculdade de avaliar melhor os problemas e propor soluções; e um grupo maior com a aptidão de decidir sobre a melhor proposta para todos. Em um governo popular, deve haver então um pequeno conselho encarregado de debater e propor as leis; e outro conselho responsável por deliberar e decretar as leis.

O primeiro conselho é denominado de Senado, formado pelos cidadãos mais ricos e prudentes, eleitos por um processo capaz de assegurar a sua seleção. O Senado irá propor as leis, mas não deliberar, já que ele representa apenas uma pequena parcela da república. A decisão deve caber ao povo, o agente naturalmente mais qualificado para deliberar a respeito do interesse do todo. Como é impraticável reunir o povo em nações com grande população ou ampla extensão territorial, a solução em termos institucionais é o estabelecimento de um segundo conselho, chamado de Assembleia do Povo, que deve reunir os representantes do povo, escolhidos em eleições livres e periódicas entre todos os cidadãos da república. Cada um dos dois conselhos é inteiramente livre em suas competências e juntos formam o Parlamento, onde reside o poder soberano da república. Desse modo, segundo Harrington (1992, p. 24), a probabilidade de que as leis civis visem interesses particulares é quase nula, porque o conselho proponente sabe que não adianta encaminhar propostas que visem apenas seu próprio interesse, já que o outro conselho não irá aprová-las; e o conselho decisório sabe que não tem condições 
de efetivar seus próprios interesses, uma vez que não pode apresentar propostas. É ainda previsto um terceiro órgão executivo, denominado simplesmente de Magistratura, cuja forma e composição variam de acordo com o tipo de república. O importante é que ele execute as leis sancionadas, preste contas de suas ações e possa ser responsabilizado diante do povo, para que as vantagens do sistema bicameral de legislação não sejam perdidas pela aplicação arbitrária das leis.

O arranjo institucional proposto é então associado ao regime misto, identificado por Harrington (1992, p.25-29) na constituição estabelecida pela vontade divina para a República de Israel e posteriormente adotada por várias cidades antigas, como Atenas, Esparta, Cartago e Roma, e também por algumas repúblicas contemporâneas, como Veneza, Suíça e Holanda. Sem entrar na discussão se o arranjo remete ao regime misto proposto por Aristóteles (1989, 1293 b - 1294 a) - uma mistura do elemento aristocrático do Senado com o elemento democrático da Assembleia do Povo, uma vez que a Magistratura só executa as leis decretadas - ou proposto por Políbio (1996, L. VI, 10-14) - uma mistura das três formas simples de governo - deve-se ressaltar que ele se diferencia do regime misto dos antigos, ao estabelecer uma divisão de tarefas - debate e decisão - no interior do poder legislativo e sua independência em relação ao poder executivo. Não se trata mais de evitar os excessos e os desvios de regimes extremos, nem de incluir e conciliar as partes constitutivas do corpo político, por meio da integração e cooperação, mas de estabelecer a separação e a especialização das diferentes funções do governo.

Se a primeira lei fundamental da república é a lei agrária, que fixa e mantém o balanço do domínio popular, a segunda lei fundamental é a lei eleitoral, que estabelece o sistema de eleição para todos os cargos públicos, desde os magistrados locais até os representantes no Senado e na Assembleia do Povo. O sistema proposto combina o sorteio aleatório dos eleitores responsáveis pela seleção dos candidatos, cujos os nomes são submetidos à votação sempre secreta das diversas assembleias, com o voto direto nos cidadãos segundo seu mérito. Ao lado do sistema eleitoral, o modelo constitucional ainda prevê a rotação no exercício dos cargos públicos, a renovação regular e periódica de eleitores e eleitos (HARRINGTON, 1992, p. 334). Assim, ao permitir a participação de todos os cidadãos, assegurando o sufrágio universal, e ao evitar o exercício contínuo do poder, que pode ser uma fonte de corrupção, a rotação completa a virtude do modelo constitucional.

Assim, se a maioria dos autores republicanos atribuía um papel primordial à virtude cívica dos cidadãos, Harrington deposita suas esperanças na virtude das instituições. O modelo constitucional proposto não pretende transformar seres humanos, impondo-lhes uma virtude 
que não lhes é natural, mas estabelecer instituições que possam promover um governo de leis e assegurar a estabilidade e a longevidade da república ${ }^{4}$.

Portanto, a imagem produzida por Pocock parece ser parcial e redutora. No que se refere ao fundamento moral da república, a presença da virtude nas instituições e nos dispositivos constitucionais parece ser mais decisiva do que a virtude cívica de cidadãos armados e prontos para lutar por sua liberdade. Além do mais, são os arranjos institucionais que permitem aos cidadãos adquirirem as disposições indispensáveis para a promoção do interesse comum.

No que se refere ao fundamento material da república, o problema não está na origem da riqueza, se é a propriedade de terras ou a propriedade de mercadorias e bens monetários, nem a sua expansão por meio do crescimento econômico. O problema está na sua distribuição desproporcional entre os cidadãos e em sua extrema concentração. A excessiva desigualdade econômica torna os cidadãos dependentes, sujeitos e submetidos à vontade dos mais ricos, o que aniquila sua liberdade e, consequentemente, a liberdade da república. Não se pode esquecer que a inspiração do modelo constitucional proposto para Oceana foi a rica república comercial de Veneza.

Assim, independentemente se a república é agrária ou comercial, a relação entre virtude e riqueza no pensamento político de Harrington é de complementaridade, na medida em que elas são os dois fundamentos do governo.

\section{REFERÊNCIAS BIBLIOGRÁFICAS}

ARISTÓTELES. Politique. Paris: Les Belles Lettres, 1989.

BARROS, A. R. G. Republicanismo Inglês: uma teoria da liberdade. São Paulo: Discurso Editorial/FAPESP, 2015.

HARRINGTON, J. The Commonwealth of Oceana and A System of Politics (ed. John A.G. Pocock). Cambridge: Cambridge University Press, 1992.

The Oceana and Other Works of James Harrington (ed. John Toland). London:

Becker and Cadell, 1771, disponível no sítio www.oll.libertyfund.org.

HOBBES, T. Leviathan. Londres: Penguin Books, 1985.

\footnotetext{
${ }^{4}$ Sobre detalhes a respeito do modelo constitucional proposto por Harrington, ver BARROS (2015, p. 446-484).
} 
The Elements of Law Natural and Politic. Oxford: Oxford University Press, 1994.

HOOKER, Richard. Of The Laws of Ecclesiastical Polity. Oxford: Oxford University Press, 2013.

LOCKE, J. Two Treatises of Government. Cambridge: Cambridge University Press, 2000.

MAQUIAVEL. N. Discursos sobre a Primeira Década de Tito Lívio. São Paulo: Martins Fontes, 2007.

PLATÃO. Lois. Paris: Les Belles Lettres, 2002.

POCOCK, J. A. G. The Machiavellian Moment: Florentine Political Thought and the Atlantic Republican Tradition. Cambridge: Cambridge University Press, 1975.

. "The Machiavellian Moment Revisited: A Study in History and Ideology". In: Journal of Modern History, vol. 53, 1981, p.49-72.

- "L'histoire de l'idéologie : les idées de Harrington après da morte". In: L'oeuvre politique de Harrington, Paris, Belin, 1995, p. 190-219.

POLÍBIO. História. Brasília: UNB, 1996. 